\title{
Cerebrospinal Fluid Monoaminergic Metabolites Differ in Wild Anubis and Hybrid (Anubis hamadryas) Baboons: Possible Relationships to Life History and Behavior
}

Jay R. Kaplan, Ph.D., Jane Phillips-Conroy, Ph.D., M. Babette Fontenot, D.V.M., M.S., Ph.D., Clifford J. Jolly, Ph.D., Lynn A. Fairbanks, Ph.D., and J. John Mann, M.D.

This article reports monoaminergic metabolite [homovanillic acid (HVA), 5-hydroxyindoleacetic acid (5HIAA), and 3-methoxy-4-hydroxyphenylglycol (MHPG)], values from the cerebrospinal fluid (CSF) of 27 wild baboons (Papio hamadryas) aged 40 to 140 months. Animals were either anubis, or anubis with hamadryas admixture; males of the latter subspecies generally have a reduced tendency to disperse from their natal groups. Overall, the values and interrelationships among the CSF monoamine metabolites resembled data reported from closely related, captive-housed animals. For example, age was significantly correlated with HVA concentrations ( $r=$ $-60, p<.05)$, but not with the other metabolites. Notably, males characterized by hamadryas admixture had significantly higher concentrations of HVA, 5-HIAA, and MHPG ( $p<.05$, respectively), a result possibly driven by differences in serotonergic activity. These data provide initial evidence that variation in central monoaminergic activity, as indicated by CSF monoamine metabolite concentrations, may reflect differences in behavior and life history that have taxonomic and, perhaps, evolutionary significance. [Neuropsychopharmacology 20: 517-524, 1999] (C) 1999 American College of

Neuropsychopharmacology. Published by Elsevier Science Inc.
KEY WORDS: Primates; Serotonin; Dopamine; Norepinephrine; CSF

From the Department of Pathology (Comparative Medicine) (JRK, $\mathrm{MBF}$ ), and Department of Anthropology, Wake Forest University School of Medicine (JRK), Winston-Salem, North Carolina; Department of Anatomy (JP-C), Washington University School of Medicine, St. Louis, Missouri; Department of Anthropology (CJJ), New York University, New York, New York; Department of Psychiatry (LAF), University of California at Los Angeles, Los Angeles, California; Department of Neuroscience (JJM), New York State Psychiatric Center, New York, New York.

Address correspondence to: Jay R. Kaplan, Ph.D., Professor of Comparative Medicine, Department of Pathology, Section of Comparative Medicine, Wake Forest University School of Medicine, Medical Center Boulevard, Winston-Salem, NC 27157-1040.

Received April 30, 1998; revised July 23, 1998; accepted August 3, 1998.
There is increasing interest in the neurobiologic factors underlying variation in social behavior, both among individuals and between species (Clarke and Boinski 1995; Young et al. 1997). Among such factors, considerable attention has focused on the relationship between behavioral characteristics and the monoaminergic neurotransmitters (serotonin, dopamine, and norepinephrine) (Kraemer and Clarke 1996). Interest in these neurotransmitters stems, in part, from the suggestion that interindividual variation in their release or uptake might be under partial genetic regulation and thereby contribute to the enduring, trait-like behavioral differences often observed among individuals within groups of primates, both human and nonhuman (Zuckerman 1991; Mulder 1992; Cloninger 1994). An extensive literature documents the inverse association between indices 
of serotonergic activity and aggressiveness in monkeys (Raleigh et al. 1986; Higley et al. 1992; Botchin et al. 1993), or violence and impulsiveness in human beings (Brown et al. 1982; Asberg et al. 1986; Linnoila et al. 1986; Berman et al. 1997; Manuck et al., 1998). Conversely, there are reports linking indices of elevated or high central serotonergic activity to positive social interaction in human subjects (Knutson et al., 1998) and monkeys (Raleigh et al., 1983; Botchin et al. 1993). Such behavioral relationships are of interest not only because of their impact on intragroup relationships but also because they might represent strategies having life history consequence.s Supporting the latter suggestion are two reports linking high serotonergic activity to delayed dispersal of free-ranging male rhesus macaques $(M a-$ caca mulatta) from their natal groups (Kaplan et al. 1995; Mehlman et al. 1995).

The evaluation of neurotransmitter profiles seems especially useful in wild populations, where natural selective agents can unmask the fitness outcomes associated with behavioral variation and its neurochemical correlates or determinants. That such studies have not been done relates in part to the relatively invasive and demanding nature of the data collection. Monoaminergic activity in the central nervous system, for example, is often assessed in monkeys by measuring serotonergic, dopaminergic, and noradrenergic metabolite concentrations in cerebrospinal fluid (CSF). The CSF, in turn, is sampled from the cisterna magna, which requires placement of a needle through the dura into the subarachnoid space surrounding the brainstem. [The existence of a rostral-caudal gradient in the monoaminergic metabolites of serotonin and dopamine suggests that cisternal sampling provides a more accurate representation of brain monoaminergic turnover than can be obtained less invasively through a more caudal (e.g., lumbar) site (Gordon et al. 1975; Shelton et al. 1988)]. Finally, once collected, the CSF must be adequately preserved. The application of these procedures under field conditions is not trivial. As a result, virtually all knowledge concerning monoamine metabolites in nonhuman primates is currently derived from laboratory and captive colony settings (Shelton et al. 1988; Higley et al. 1992; Raleigh et al. 1992; Clarke et al. 1995; Kaplan et al. 1995). In addition to the above-referenced association between low serotonergic activity (as indicated by CSF metabolite concentrations) and early dispersal, these studies often report high correlations among the monoamine metabolites and a significant age-related decline in dopaminergic, and perhaps serotonergic, activity. It would be useful to determine whether such relationships extend to populations in their native habitat.

The foregoing considerations led us to undertake a pilot investigation evaluating the neurochemical profiles of anubis (Papio hamadryas anubis) and hamadryas (P. h. hamadryas) baboons. [The grivet monkeys (Cerco- pithecus aethiops aethiops) that also live in the Awash Valley were subjected to a similar investigation; the results of this latter study are reported elsewhere (Fairbanks et al., unpublished results).] The two baboon forms differ significantly in social behavior as well as appearance. One distinction of potential interest with respect to central monoaminergic activity involves male dispersal. Like most macaques, anubis baboons live in multimale-multifemale troops characterized by almost universal male dispersal and strong female philopatry (Pusey and Packer 1987). In contrast, hamadryas males rarely move permanently from their natal group, or band, where they normally remain in close contact with male kin (their "clan") throughout their lives (Kummer 1968; Abegglen 1984; but see also Phillips-Conroy et al. 1992). Perhaps as a correlate of their philopatry, hamadryas males exhibit affiliative and mutually supportive behavior in a variety of social contexts in which anubis males tend to be indifferent or hostile to each other (Nystrom 1992).

These behavioral contrasts, and the existence of hybrids formed by interbreeding between the two baboon forms (Nagel 1973; Phillips-Conroy and Jolly 1986), suggested three objectives for a pilot study: (1) to establish the feasibility of collecting neurochemical data under field conditions; (2) to compare the monoamine metabolite values obtained from animals captured in their native habitat and natural social context with those reported from laboratory and colony populations; and (3) to conduct an initial test of the hypothesis that serotonergic metabolite concentrations would differ in the two parental baboon forms, and their hybrids, in ways consistent with the distinct behavioral characteristics of the parental populations. In this pilot study, sampling was limited to one anubis and one hybrid group. From the previously established relationship between dispersal and serotonergic activity in male rhesus, and the observation that the tendency to disperse in early adulthood is much less pronounced among hamadryas than among anubis males, we predicted that the level of serotonin metabolites in males with hamadryas admixture would be higher than in their "pure" anubis counterparts.

\section{METHODS}

\section{Study Site and Animals}

The study site was in the Awash National Park (ANP), approximately $200 \mathrm{~km}$ east of Addis Ababa, Ethiopia, within the East African Rift Valley. The altitude (about $1000 \mathrm{~m}$ above sea level) and natural vegetation of the park are intermediate between those of the Ethiopian high plateau and the semi-desert foothills and lowlands of the Danakil region (Jacobs and Schloeder 1993), 
which are, respectively, typical anubis and hamadryas habitats. In the ANP, hamadryas baboon groups (about 100-150 animals) forage in palm groves and dry thornbush. The ranges of seven anubis baboon troops (15-120 animals each) are centered upon the narrow evergreen forest strip along the perennial Awash river (Nagel 1973; Phillips-Conroy and Jolly (1986; Jacobs and Schloeder 1993). A zone about $30 \mathrm{~km}$ wide between them is occupied by groups of baboons of intermediate appearance, evidently the product of hybridization. The Awash baboon populations have been sampled repeatedly by capture/release, as part of a long-term study designed to investigate morphologic, physiologic, and genetic variation. The 27 animals ( 22 males, 5 females) reported here are derived from an anubis group of about 60 animals, showing minimal hamadryas admixture (Group F) and a similarly-sized group consisting almost entirely of phenotypic hybrids (Group H) (Phillips-Conroy et al. 1992).

\section{Trapping and Field Evaluation}

All captures were made in the morning (between 6:00 and 11:00 A.M.), after several days of prebaiting (Brett et al. 1982). Animals were lured with corn into individual cage-traps that were closed manually by an observer. All of the adult male anubis were caught singly; a few adult male hybrids, however, were accompanied by one or even two other animals. Captives remained in the trap, untranquilized, for 10 to $120 \mathrm{~min}$. They were then tranquilized, serially, with intramuscular ketamine administered via a pole syringe $(10 \mathrm{mg} / \mathrm{kg}$, weight judged by eye), and carried to a work site about $50 \mathrm{~m}$ away, where a variety of data and samples, including body weights and casts of the upper left dental quadrant, were collected according to an established protocol (Brett et al. 1982; Phillips-Conroy et al. 1992; Nystrom 1992). The age of each animal (in months) was estimated from its dental complement and from the degree of molar attrition visible in its dental cast, when compared with casts from a series from animals of known age (Phillips-Conroy and Jolly 1988; PhillipsConroy and Bergman, in press). After sampling and examination, the animals were allowed to recover spontaneously, generally with $90 \mathrm{~min}$ of initial tranquilization. All recoveries were medically uneventful. Sampled animals (readily identifiable by their shaved napes) were seen to rejoin their social groups and were observed interacting normally on subsequent occasions.

\section{Collection and Preservation of CSF}

The animal to be sampled was placed on its right side, with the head flexed. The hair on the occiput was clipped, and the skin cleaned with alcohol followed by a betadine solution. A sterile 3-cc syringe was fitted with a 25-gauge $\times 2.5$-inch needle. The needle was inserted at the point where the midline intersected a transverse line joining the cranial edges of the wings of the atlas. Slight suction was applied as the tip of the needle passed through skin, muscle, and fascia into the cisterna magna, and penetration of the subarachnoid space was detected by flow of CSF into the syringe. When approximately $1.5-3.0 \mathrm{ml}$ of CSF had been obtained, suction was released, the needle carefully withdrawn, and the sample injected into a polypropylene vial containing $100 \mathrm{ng}$ glutathione. The vials were placed in a wet cloth bag and allowed to cool by evaporation. Eight to $13 \mathrm{~h}$ later they were placed in liquid nitrogen and remained frozen until assay.

To determine the effect of short-term storage at ambient temperature, CSF samples were obtained from four adult male cynomolgus macaques at the laboratory of JRK. The samples from each animal were equally divided into four, 2.0-ml polypropylene vials. Following collection, one vial was immediately placed on dry ice, then frozen at $-70^{\circ} \mathrm{C}$. The remaining three vials, each containing $100 \mathrm{ng}$ glutathione, were exposed to ambient summer temperatures $\left(23-29.6^{\circ} \mathrm{C}\right)$ for $8 \mathrm{~h}$, then frozen at $-70^{\circ}$. All of the samples were then analyzed by the techniques described in the Methods. The results indicated that there were no significant difference in monoamine metabolite concentrations (Frozen: 5-HIAA, $362 \pm$ 51 [SEM] pmol/ml; HVA, $1324 \pm 98 \mathrm{pmol} / \mathrm{ml} ; \mathrm{MHPG}$, $50 \pm 4 \mathrm{pmol} / \mathrm{ml}$; Ambient: 5-HIAA, $343 \pm 43 \mathrm{pmol} / \mathrm{ml}$; HVA, $1370 \pm 90 \mathrm{pmol} / \mathrm{ml}$; MHPG, $57 \pm 4 \mathrm{pmol} / \mathrm{ml}$ ). Furthermore, the monoaminergic metabolite concentrations in the frozen samples were significantly correlated with those assayed in the samples that had remained at ambient temperature for eight $h$ (5-HIAA: $r=1.0$; HVA: $r=1.0$; MHPG: $r=0.95$ ).

\section{Assessment of Monoamine Metabolites in CSF}

All monoaminergic values reported and discussed here [collected from cynomolgus macaques (Macaca facicularis) at Wake Forest University School of Medicine, Winston-Salem, North Carolina; rhesus macaques at Cayo Santiago, Puerto Rico; baboons at Southwest Foundation for Biomedical Research, San Antonio, Texas; as well as baboons at ANP] were assayed in the same laboratory by identical methods. As part of this method, a precisely measured aliquot of each sample was mixed with an equal volume of cold mobile phase. The mixture was then filtered by centrifugation $(6000 \mathrm{~g}$ for $40 \mathrm{~min}$ at $4^{\circ} \mathrm{C}$ ), and part of the filtrate transferred to a 300-FL microinjection insert. This material was then analyzed by high-performance liquid chromatography with electrochemical detection, according to the method of Scheinin et al. (1983). This allows simultaneous evaluation of the three major monoaminergic metabolites in CSF: (1) 3-methoxy-4-hydroxyphenylgly- 
col (MHPG), the noradrenergic metabolite; (2) 5-hydroxyindoleacetic acid (5-HIAA), the serotonergic metabolite; and (3) homovanillic acid (HVA), the dopaminergic metabolite. The main source of 5-HIAA and HVA is the brain, as evidenced by the concentration gradient in CSF, and correlations between brain and CSF levels of 5-HIAA. MHPG does not have a concentration gradient and probably reflects contributions from blood and spinal cord. Although they generally reflect neuronal activity because a small proportion of released neurotransmitter is metabolized by monoamine oxidase after release and reuptake at the nerve terminal and before vesicular uptake, these metabolites are only indirect indices of neuronal activity because they are also affected by factors that alter catabolic rates independent of neuronal firing (Commissiong 1985).

\section{Data Analysis}

Before analysis, all metabolite values were subjected to a square-root transformation to normalize their distributions and reduce variance; however, only untransformed values are reported. In a further data transformation, we regressed the 5-HIAA values onto the HVA data and used the residuals so obtained as an "HVAfree" index of serotonergic activity. This was done because of the typically high correlation between CSF 5-HIAA and HVA and because of our hypothesis that serotonergic activity, in particular, would differ between the anubis baboons and those with hamadryas admixture. Preliminary analysis showed that the residuals were not significantly correlated with either HVA (by definition, $\mathrm{r}_{27}=0$ ) or MHPG $\left(\mathrm{r}_{27}=0.19, \mathrm{NS}\right)$.

Table 1. Central Monoaminergic Metabolites in Baboons Living in the Awash National Park $^{a, b}$

\begin{tabular}{|c|c|c|c|c|c|c|}
\hline Monkey & Group & HVA & HIAA & MHGP & SEX & $\begin{array}{c}\text { Age } \\
\text { (months) }\end{array}$ \\
\hline 95002 & $\mathrm{~F}$ & 411 & 76 & 50 & $\mathrm{M}$ & 100 \\
\hline 95003 & F & 665 & 156 & 126 & M & 143 \\
\hline 95004 & F & 1332 & 259 & 170 & F & 55 \\
\hline 95005 & F & 819 & 183 & 102 & M & 170 \\
\hline 95006 & F & 1259 & 245 & 164 & M & 52 \\
\hline 95007 & F & 1100 & 214 & 188 & M & 66 \\
\hline 95008 & F & 1321 & 231 & 234 & M & 76 \\
\hline 95011 & $\mathrm{~F}$ & 1162 & 213 & 185 & M & 68 \\
\hline 95015 & $\mathrm{~F}$ & 691 & 194 & 114 & F & 100 \\
\hline 95016 & $\mathrm{~F}$ & 1735 & 395 & 215 & M & 33 \\
\hline 95020 & $\mathrm{~F}$ & 1938 & 302 & 217 & M & 12 \\
\hline 95021 & $\mathrm{~F}$ & 1444 & 188 & 130 & M & 33 \\
\hline 95023 & $\mathrm{H}$ & 904 & 196 & 172 & M & 98 \\
\hline 95024 & $\mathrm{H}$ & 688 & 350 & 173 & M & 160 \\
\hline 95027 & $\mathrm{H}$ & 1447 & 190 & 250 & M & 98 \\
\hline 95028 & $\mathrm{H}$ & 1388 & 637 & 219 & M & 100 \\
\hline 95029 & $\mathrm{H}$ & 2611 & 511 & 344 & M & 68 \\
\hline 95033 & $\mathrm{H}$ & 2504 & 511 & 327 & M & 52 \\
\hline 95034 & $\mathrm{H}$ & 1596 & 344 & 188 & M & 52 \\
\hline 95035 & $\mathrm{H}$ & 911 & 266 & 168 & M & 180 \\
\hline 95038 & $\mathrm{H}$ & 1184 & 292 & 168 & M & 68 \\
\hline 95039 & $\mathrm{H}$ & 1233 & 294 & 170 & M & 57 \\
\hline 95041 & $\mathrm{H}$ & 1492 & 297 & 255 & F & 180 \\
\hline 95043 & $\mathrm{H}$ & 773 & 195 & 127 & F & 150 \\
\hline 95044 & $\mathrm{H}$ & 1570 & 273 & 227 & F & 45 \\
\hline 95045 & $\mathrm{H}$ & 1325 & 308 & 249 & M & 76 \\
\hline 95046 & $\mathrm{H}$ & 1822 & 336 & 256 & $\mathrm{M}$ & 25 \\
\hline \multicolumn{7}{|l|}{ Mean values $( \pm$ SEM $)$} \\
\hline $\begin{array}{l}\text { Awash baboons } \\
\text { ( } 27 \text { baboons and females) }\end{array}$ & & $1308(100)$ & $283(23)$ & $192(13)$ & & \\
\hline $\begin{array}{l}\text { Cayo Santiago rhesus } \\
\text { (60 adult males })^{c}\end{array}$ & & $1456(55)$ & $232(9)$ & $127(4)$ & & \\
\hline $\begin{array}{l}\text { Wake Forest Cynomolgus } \\
\text { (4 adult males })^{d}\end{array}$ & & $1370(90)$ & $343(43)$ & $57(4)$ & & \\
\hline
\end{tabular}

${ }^{a}$ Two sets of male macaques included for comparison purposes.

${ }^{b}$ Monoamine values in $\mathrm{pmol} / \mathrm{ml}$.

${ }^{c}$ Kaplan et a. 1995.

${ }^{d}$ See text for more detail. 
The analytic strategy was as follows. Monoaminergic metabolites and age were first subjected to a correlation analysis. Values for adults were then compared by sex, without regard to group of origin (anubis or hybrid). Finally ,hybrid and anubis males were compared by analysis of covariance (ANCOVA), using age as the covariate. All tests of significance were two-tailed.

\section{RESULTS}

Table 1 contains individual monoaminergic metabolite values and ancillary data from individual ANP animals together with the means ( $\pm \mathrm{SD}$ ) for the entire sample, by variable. For comparison purposes, this table also contains mean monoamine metabolite data collected from cynomolgus monkeys (M. fascicularis) in North Carolina under similar temperature conditions and from rhesus monkeys at Cayo Santiago (Kaplan et al. 1995). The 5-HIAA residuals are not included in Table 1 , as they were calculated separately, depending upon which animals were involved in any particular analysis (e.g., all animals, all males). Table 1 indicates that monoamine metabolite values from the ANP baboons fell within the range observed in macaques, except for MHPG.

Table 2 shows the correlations among monoamine values and age for all animals $(n=27)$. The correlations among all of the metabolites are significant and high, as is the inverse correlation between HVA and age. Limiting the analysis to males did not alter the direction or strength of any correlation. Finally, a comparison (by ANCOVA with age as the covariate) between all males $(n=22)$ and all females $(n=5)$ revealed no significant differences for any metabolite, or for the 5-HIAA residual index $(F<0.50, N S)$. Nor were there any significant monoaminergic differences between the sexes when the analysis was limited to the eight males and three females that were all fully adult ( $>96$ months) $\mathrm{F}<0.05$, NS).

We next compared monoamine metabolite values in males of all ages by group membership (anubis troop "F", $n=10$; hybrid troop " $\mathrm{H}$ " $n=12$ ) to test the prediction that hamadryas admixture in the hybrids would be

Table 2. Correlations Among All Animals $(n=27)$

\begin{tabular}{lccccc}
\hline & & \multicolumn{3}{c}{ Residualized } \\
& HVA & HIAA & HIAA & MHPG & Age \\
\hline HVA & - & $0.71^{*}$ & 0.00 & $0.86^{*}$ & $-0.60^{*}$ \\
5-HIAA & & - & $0.70^{*}$ & $0.75^{*}$ & -0.23 \\
Residualized & & & - & 0.19 & -0.27 \\
$\quad$ HIAA & & & - & - & -0.32 \\
MHPG & & & & & - \\
Age & & & & & \\
\hline${ }^{*} p<.001$ & & & & &
\end{tabular}

associated with altered central monoaminergic activity. There was no significant difference in mean age between males from $\mathrm{F}$ and $\mathrm{H}$ (Mean $\pm \mathrm{SD}=75.3 \pm 49.9$ and $86.2 \pm 45.1$ months, respectively $F<0.5$, NS). However, as indicated in Table 2, age showed a significant, inverse correlation with HVA and directionally similar correlations with the other metabolites. Furthermore, all of the monoamines were highly intercorrelated. Accordingly, an ANCOVA with age as the covariate was used for all comparisons between group $\mathrm{F}$ and $\mathrm{H}$ males. The results of these comparisons are depicted in Figure 1. Hybrid males exhibited significantly higher concentrations of each of the metabolites. The 5-HIAA residuals also differentiated the groups, and, since the residuals are uncorrelated with either HVA or MHPG, this effect is probably not driven by covariation with either of these metabolites.

\section{DISCUSSION}

The current investigation produced four major results, First is the practical demonstration that it is feasible to obtain CSF by cisternal puncture from fully wild animals at a remote field site, with no discernible adverse medical or behavioral effects upon the subjects, and that metabolite preservation comparable to that obtained under laboratory conditions can be achieved. Although cisternal CSF samples have previously been obtained outside of the laboratory (Higley et al. 1991; Kaplan et al. 1995), to our knowledge, this is the first time that they have been collected from wild animals. Preliminary experiments with CSF from macaques showed that the addition of glutathione to the sample tubes could prevent significant degradation of the monoamine metabolites, even at ambient temperatures comparable to those experienced at the field site. Though kept at ambient temperature for several hours before freezing, the ANP samples yielded metabolite concentrations within, or even slightly above, the range found in previous studies of nonhuman primates (Kaplan et al. 1994; Kaplan et al. 1995).

Second, our results, when compared with those of previous studies (Table 1), suggest an environmental effect on the CSF concentration of MHPG but not the other two metabolites. Specifically, MHPG was present in significantly higher concentrations among the ANP baboons than in indoor-housed M. fascicularis or freeranging rhesus monkeys. In contrast, the other two metabolites fell within the range reported by us and others for macaques and vervets (Mehlman et al. 1995; Raleigh et al. 1992; Kaplan et al. 1995). It is tempting to dismiss the variation in MHPG concentration as due to differences among species or as artifacts of differential preservation. However, unpublished data from 91 adult male and female baboons housed in small groups at the 

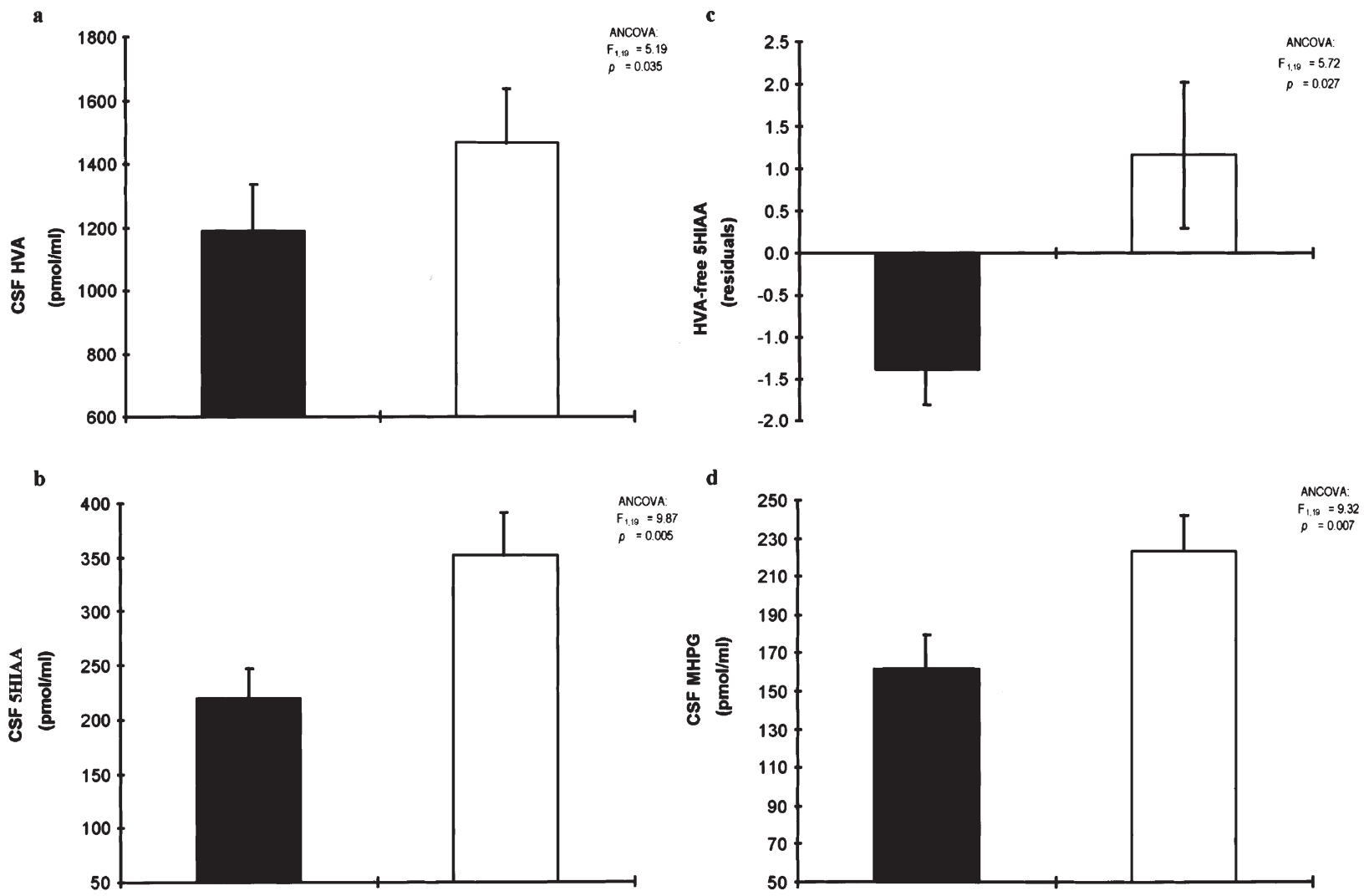

Figure 1. Mean values of CSF monoamine metabolites [(a): HVA; (b): 5-HIAA; (c): residual values of 5-HIAA; and (d): MHPG among males from groups $\mathrm{F}(\boldsymbol{\square}, n=10$ anubis) and $\mathrm{H}(\square, n=11$ hybrid); groups compared by analysis of covariance with age in months as the covariate.

Southwest Foundation for Biomedical Research produced a mean MHPG value $(83 \pm 31 \mathrm{pmol} / \mathrm{ml})$ closer to that of similarly housed cynomolgus macaques than to values seen either in free-ranging rhesus or in ANP baboons. Furthermore, others have reported "unexplained" variability in MHPG (but not HVA or 5-HIAA) among rhesus monkeys housed in different geographic locations (Shelton et al. 1988). It is thus possible that environmental factors such as stress influence MHPG concentrations to a greater extent than those of the other monoaminergic metabolites. In fact, there is evidence from both nonhuman primates and rodents indicating that acute stress causes an increase in sympathetic activity that appears to be associated with an increase in brain and CSF MHPG (e.g., Hellriegel and D'Mello 1997; Higley, Suomi and Linnoila 1991).

A third set of findings concerned the relationships among the monoamine metabolites and between the metabolites and age. As in previous work, the present study found relatively high correlations among the monoamines, particularly between HVA and 5-HIAA (Raleigh et al. 1983; Kaplan et al. 1995; Mehlman et al. 1994). Significant correlations between these metabolites and MHPG have been seen previously in our laboratory (Kaplan et al. 1994; Kaplan et al. 1995) but gener- ally have not been reported by others (Mehlman et al. 1994). In fact, the current data set contains an unusually high correlation between MHPG and each of the other metabolites. One possibility for the level of correlation observed in this study is that the monoamine oxidase (MAO) functional reserve may be less in wild baboons than in captive animals, and therefore have a substantially greater influence in regulating the monoamines. With respect to this possibility, data from African green monkeys (Cercopithecus aethiops) and two Asian macaques suggest there is relatively little variation in brain MAO across species (Riachi and Harik 1992). Alternatively, in wild animals, there could be a higher correlation in neuronal activity across these three related neurotransmitter systems. Finally, the high correlation could represent a chance finding in this relatively small population. Data collections in progress from wild baboons should help resolve this issue.

The current data also revealed an inverse relationship between all of the metabolite concentrations and age, though it was statistically significant only for HVA. The literature relating age to monoamine concentrations is often difficult to interpret due to constricted age ranges, mixed cross-sectional and longitudinal data, and (among humans) the frequent use of popula- 
tions compromised by illness (e.g., monkeys: Raleigh et al. 1992; Higley et al. 1991; Shelton et al. 1988; human beings: Bowers and Gerbode 1968; Kruesi et al. 1988; Seifert et al. 1980; Tohgi et al. 1993). Nonetheless, a decline in HVA with age has been consistently observed in macaque populations (Shelton et al. 1988; Higley et al. 1991). There is one report indicating that MHPG declines with age in monkeys (Shelton et al. 1988), and conflicting reports concerning age-associated change in 5-HIAA (Raleigh et al. 1992; Higley et al. 1991; Shelton et al. 1988). The results from the present set of wild baboons are convincing regarding an age effect on HVA but are indeterminate with respect to MHPG and 5-HIAA.

Finally, there was significantly greater monoaminergic activity in the hybrid male baboons than in their anubis counterparts, as indicated by higher concentrations of all three metabolites. The high correlation among them makes this outcome somewhat difficult to interpret. As indicated above, the differences between the two groups of baboons could reflect the influence of MAO activity. The 5-HIAA residuals, however, were also relatively high in hybrid males, despite being uncorrelated with either MHPG or HVA. The latter outcome suggests that there may have been a specific serotonergic difference between the anubis and the hybrids, as initially predicted. If this interpretation is correct, the difference between "pure" anubis and hybrids whose anubis ancestry is tempered with hamadryas admixture is consistent with behavioral differences between the two parental forms (Nagel 1973; Nystrom 1992). This conclusion is necessarily constrained by the relatively small sample size and the lack of data from unhybridized hamadryas populations. Furthermore, monoamine metabolite concentrations represent only an indirect index of central monoaminergic activity. In addition, the data do not resolve the question of causality; behavioral differences between the baboon types could arise ontogenetically for undetermined reasons, with the monoamines changing in response to behavior. Nevertheless, in our view, the data reported here provide intriguing initial evidence that taxonomically relevant differences in nonhuman primate social behavior may reflect underlying divergence in neurochemical activity.

\section{ACKNOWLEDGMENTS}

The authors thank the graduate students from Washington University and New York University for their contributions in the field, and Dr. Sven Britten and the Amauer Hansen Research Institute for providing the liquid nitrogen and dry ice. William Melaga (UCLA) and two anonymous reviewers provided helpful clarifications regarding interpretation of the data. Research in the Awash National Park was supported, in part, by the following grants: SR9615150 (JPR, CMJ), MH46745 (JJM), HL40962 (JRK), and Novo Nordisk (JRK). The field work was conducted with the permission from the Ethiopian
Wildlife Conservation Organization and in association with the Department of Biology, Addis Ababa University.

\section{REFERENCES}

Abegglen JJ (1984): On Socialization in Hamadryas Baboons. Cranbury, NJ, Associated University Presses

Asberg M, Nordstrom P, Traskman-Bendz L (1986): Cerebrospinal fluid studies in suicide. An overview. Ann NY Acad Sci 9(Suppl 4):374-376

Berman ME, Kavoussi RJ, Coccaro EF (1997): Neurotransmitter correlates of human aggression. In Stouff DM, Breiling J, Maser JD (eds), Handbook of Antisocial Behavior. New York, John Wiley and Sons, Inc., pp 305313

Botchin MB, Kaplan JR, Manuck SB, Mann JJ (1993): Low versus high prolactin responders to fenfluramine challenge: marker of behavioral differences in adult male cynomolgus macaques. Neuropsychopharmacol 9:93-99

Bowers MB, Gerbode FA (1968): Relationship of monoamine metabolites in human cerebrospinal fluid to age. Nature 219:1256-1257

Brett FL, Turner TR, Jolly CJ, Cauble RG (1982): Trapping baboons and vervet monkeys from wild, free-ranging populations. J Wildlife Manag 46:164-174

Brown GL, Ebert MH, Goyer PF, Jimerson DC, Klein WJ, Bunney WE, Goodwin FK (1982): Aggression, suicide, and serotonin: relationships to CSF amine metabolites. Am J Psychiatry 139:741-746

Clarke AS, Kammerer CM, George KP, Kupfer DJ, McKinney WT, Spence MA, Kraemer GW (1995): Evidence for heritability of biogenic amine levels in the cerebrospinal fluid of rhesus monkeys. Biol Psychiatry 38:572-577

Clarke AS, Boinski S (1995): Temperament in nonhuman primates. Am J Primatol 37(2): 103-126

Cloninger CR (1994): Temperament and personality. Curr Opin Neurobiol 4:266-273

Commissiong JW (1985): Monoamine metabolites: their relationship and lack of relationship to monoaminergic neuronal activity. Biochem Pharmacol 34(8):1127-1131

Gordon E, Perlow M, Oliver J, Ebert M, Kopin I (1975): Origins of catecholamine metabolites in monkey cerebrospinal fluid. J Neurochem 25:347-349

Hellriegel ET, D'Mello AP (1997): The effect of acute, chronic and chronic intermittent stress on the central noradrenergic system. Pharmacol Biochem Behav 57(1-2):207-214

Higley JD, Suomi SJ, Linnoila M (1991): CSF monoamine metabolite concentrations vary according to age, rearing, and sex, and are influenced by the stressor of social separation in rhesus monkeys. Psychopharmacol 103(4): 551-556

Higley JD, Mehlman PT, Taub DM, Higley SB, Suomi SJ, Linnoila M, Vickers JH (1992): Cerebrospinal fluid monoamine and adrenal correlates of aggression in freeranging rhesus monkeys. Arch Gen Psychiatry 49:436-441

Jacobs MJ, Schloeder CA (1993): The Awash National Park Management Plan: Report Presented to the Ethiopian Wildlife Conservation Organization. 
Kaplan JR, Shively CA, Fontenot MB, Morgan TM, Howell SM, Manuck SB, Muldoon MF, Mann JJ (1994): Demonstration of an association among dietary cholesterol, central serotonergic activity, and social behavior in monkeys. Psychosom Med 56(6):479-484

Kaplan JR, Fontenot MB, Berard J, Manuck SB, Mann JJ (1995): Delayed dispersal and elevated monoaminergic activity in free-ranging rhesus monkeys. Am J Primatol 35:29-234

Knutson B, Wolkowitz OM, Cole SW, Chan TC, Moore EA, Johnson RC, Terpstra J, Turner RA, Reus VI (1998): Selective alteration of personality and social behavior by serotonergic intervention. Am J Psychiatry 155(3): 373-379

Kraemer GW, Clarke AS (1996): Social attachment, brain function, and aggression. Ann NY Acad Sci 20:794:121135

Kruesi MJ, Swedo SE, Hamburger SD, Potter WZ, Rapoport JL (1988): Concentration gradient of CSF monoamine metabolites in children and adolescents. Biol Psychiatry 24(5):507-514

Kummer H (1968): Social Organization of Hamadryas baboons. Chicago, University of Chicago Press

Linnoila M, Virkkunen M, Roy A (1986): Biochemical aspects of aggression in man. Clin Neuropharmacol 9(Suppl 4):377-379

Manuck SB, Flory JD, McCaffrey JM, Matthews KA, Mann JJ, Muldoon MF (1998): Aggression, impulsivity and central nervous system serotonergic responsivity in a nonpatient sample. Neuropsychopharmacology 19:287-299

Mehlman PT, Higley JD, Faucher I, Lilly AA, Taub DM, Vickers J, Suomi SJ, Linnoila M (1994): Low CSF 5-HIAA concentrations and severe aggression and impaired impulsive control in nonhuman primates. Am J Psychiatry 15(10):1485-1491

Mehlman PT, Higley JD, Faucher I, Lilly AA, Taub DM, Vickers J, Suomi SJ, Linnoila M (1995): Correlation of CSF 5-HIAA concentration with sociality and the timing of emigration in free-ranging primates. Am J Psychiatry 152(6):907-913

Mulder R (1992): The biology of personality. Aust NZ J Psychiatry 26:364-376

Nagel U (1973): A comparison of anubis baboons, hamadryas baboons, and their hybrids at a species border in Ethiopia. Folia Primat 19:104-165

Nystrom PD (1992): Mating Success of Hamadryas, Anubis and Hybrid Male Baboons in a "Mixed" Social Group in the Awash National Park, Ethiopia. PhD dissertation, Washington University, St. Louis, MO

Phillips-Conroy JE, Jolly CJ (1986): Changes in the structure of the baboon hybrid zone in the Awash National Park, Ethipia. Am J Phys Anthropol 71:337-349

Phillips-Conroy JE, Jolly CJ (1988): Scheduling of dental eruption in wild and captive baboons. Am J Primatol 15:1-13
Phillips-Conroy JE, Jolly CJ, Nystrom P, Hemmalin H (1992): Migration in male hamadryas baboons of the Awash National Park, Ethiopia. Int J Primatol 13:455-476

Phillips-Conroy JE, Bergman TJ (In press): Quantitative assessment of occlusal wear and age estimation in Ethiopian baboons. In Jolly CE, Whitehead P (eds), Old World Monkeys. Cambridge, UK, Cambridge University Press

Pusey AE, Packer C (1987): Dispersal and philopatry. In Smuts BB, Cheney DL, Seyfarth RM, Wrangham RW, Struhsaker TT (eds), Primate Societies. Chicago, IL, University of Chicago Press, pp 250-266

Raleigh MJ, Brammer GL, McGuire MT (1983): Male dominance, serotonergic systems, and the behavioral and physiological effects of drugs in vervet monkeys (Cercopithecus aethiops sabaeus). In KA Miczek (ed), Ethopharmacology: Primate Models of Neuropsychiatric Disorders. New York, Alan R. Liss, pp 185-198

Raleigh MJ, Brammer GL, Ritvo ER, Geller E, McGuire MT, Yuwiler A (1986): Effects of chronic fenfluramine on blood serotonin, cerebrospinal fluid metabolites, and behavior in monkeys. Psychopharmacol 90:503-508

Raleigh MJ, Brammer GL, McGuire MT, Pollack DB, Yuwiler A (1992): Individual differences in basal cisternal cerebrospinal fluid 5-HIAA and HVA in monkeys. The effects of gender, age, physical characteristics, and matrilineal influences. Neuropsychopharmacol 7:295-304

Riachi NJ, Harik SI (1992): Monoamine oxidases of the brains and livers of macaque and cercopithecus monkeys. Exp Neurol 115:212-217

Scheinin M, Chang WH, Kirk KL, Linnoila M (1983): Simultaneous determination of 3-methoxy-4-hydroxyphenylglycol, 5-hydroxyindoleacetic acid, and homovanillic acid in cerebrospinal fluid with high-performance liquid chromatography using electrochemical detection. Anal Biochem 131(1):246-253

Seifert WE, Foxx JF, Butler IJ (1980): Age effect on dopamine and serotonin metabolite levels in cerebrospinal fluid. Ann Neurol 8:38-42

Shelton SE, Kalin NH, Gluck JP, Kereztury MF, Schneider VA, Lewis MH (1988): Effect of age on cisternal cerebrospinal fluid concentrations of monoamine metabolites in nonhuman primates. Neurochem Int 13:33533357

Tohgi H, Takahashi S, Abe T (1993): The effect of age on concentrations of monoamines, amino acids, and their related substances in the cerebrospinal fluid. J Neural Transmission 5:215-226

Young LJ, Winslow JT, Nilsen R, Insel TR (1997): Species differences in $\mathrm{V} 1 \mathrm{a}$ receptor gene expression in monogamous and nonmonogamous voles: behavioral consequences. Behav Neurosci 11:599-605

Zuckerman M (1991): Psychobiology of Personality. Cambridge, UK, Cambridge University Press 